\title{
The health system cost of post-abortion care in Uganda
}

\author{
Michael Vlassoff, ${ }^{1 *}$ Frederick Mugisha, ${ }^{2}$ Aparna Sundaram, ${ }^{1}$ Akinrinola Bankole, ${ }^{1}$ Susheela Singh, \\ Leo Amanya, ${ }^{3}$ Charles Kiggundu ${ }^{4}$ and Florence Mirembe ${ }^{4}$
}

${ }^{1}$ Guttmacher Institute, 125 Maiden Lane, 7th Floor, New York, NY 10038, USA, ${ }^{2}$ Gish Africa, Box 208, Kyambogo, Kampala, Uganda, ${ }^{3}$ Independent Consultant, c/o Gish Africa, Box 208, Kyambogo, Kampala, Uganda and ${ }^{4}$ Makerere College of Health Sciences, Makerere University, P.O. Box 7072, Kampala, Uganda

*Corresponding author. Senior Research Associate, Guttmacher Institute, 125 Maiden Lane, New York, NY, USA.

E-mail: mvlassoff@guttmacher.org

\section{Accepted 27 November 2012}

This article presents estimates based on the research conducted in 2010 of the cost to the Ugandan health system of providing post-abortion care (PAC), filling a gap in knowledge of the cost of unsafe abortion. Thirty-nine public and private health facilities were sampled representing three levels of health care, and data were collected on drugs, supplies, material, personnel time and out-of-pocket expenses. In addition, direct non-medical costs in the form of overhead and capital costs were also measured. Our results show that the average annual PAC cost per client, across five types of abortion complications, was \$131. The total cost of PAC nationally, including direct non-medical costs, was estimated to be $\$ 13.9$ million per year. Satisfying all demand for PAC would raise the national cost to $\$ 20.8$ million per year. This shows that PAC consumes a substantial portion of the total expenditure in reproductive health in Uganda. Investing more resources in family planning programmes to prevent unwanted and mistimed pregnancies would help reduce health systems costs.

Keywords abortion, cost, post-abortion care, Uganda

\section{KEY MESSAGES}

- Post-abortion care consumes significant health resources in Uganda.

- Investing more in family planning programmes to prevent unwanted pregnancies would bring net financial benefits.

\section{Introduction}

In Uganda, deaths of women from complications of pregnancy or childbirth are unacceptably high and the maternal mortality ratio is estimated to be 310 maternal deaths per 100000 live births (WHO 2012). As legal abortion in Uganda remains highly restricted and unmet need for contraception is high, many women seek abortions in unsafe conditions, often from unskilled providers. This has made unsafe abortion one of the leading causes of maternal mortality in Uganda. A 2003 study of abortion incidence in Uganda showed that abortion rates were among the highest in the developing world, and unsafe abortion was a major reproductive health issue (Singh et al. 2005). Although the health consequences of unsafe abortions are fairly well known, there is scant knowledge of the costs to the Ugandan health system and to the women and their households. By showing how much the country will save if recourse to unsafe abortion is prevented, the study provides important evidence supporting need for policy and programme change to lower the high incidence of unsafe abortion.

Caring for women with complications of unsafe abortion often requires expensive treatment in terms of skilled personnel, surgical procedures, expensive drugs and supplies and prolonged hospital stays (Johnston et al. 2007; Henshaw et al. 
2008; Prada et al. 2005; Vlassoff et al. 2008), and unsafe abortion continues to be a major contributor to the case load of maternal and gynaecological services of the Ugandan health system. However, studies on the costs of unsafe abortion to health systems at the national level are limited, and attempts to measure costs at the regional level have been made only recently (Vlassoff et al. 2008, 2009a). A review of the literature reveals that little research has been conducted on the direct economic costs to women and households, or to national health systems in sub-Saharan Africa (Woog et al. 2007).

With regard to Uganda, three studies have looked at the cost of unsafe abortion. Johnston et al. (2007) estimated the cost of post-abortion care (PAC) using data from a 1994 application of the Mother-Baby Package costing spreadsheet to one district of Uganda (Mbarara). Looking only at direct medical inputs the study estimated an overall cost of $\$ 44.87$. A second study (Levin et al. 2003) collected cost data at two facilities in Masaka district in 1998 on direct medical inputs and some overhead costs. They estimated that $\$ 37.70$ in direct medical inputs were spent per PAC case and $\$ 8.82$ in direct non-medical inputs. ${ }^{1}$ These two studies are based on data from the 1990s, indicating a need for evidence on the current situation, as well as estimates that include direct non-medical costs and that are more broadly representative of the situation in the country as a whole. A third and recent study, Babigumira et al. (2011), used a decision-analysis model, applied to data from Mbarara referral hospital inter alia, to estimate both societal costs and health-system costs of induced abortion in Uganda. It found that each induced abortion incurs a total cost of $\$ 177$, of which $\$ 85$ is the direct medical and non-medical cost to the health system and $\$ 92$ is the indirect cost due to lost productivity. Our study uses a health-system perspective and so does not attempt to estimate indirect, societal costs. ${ }^{2}$ This study expands on the study by Babigumira et al. by providing detailed cost estimates based on an extensive set of current primary data collected through a nationwide survey.

\section{Data and methods}

This study is based on data collected from a sample of 39 health facilities in August-November 2010. This sample was purposively selected and was designed to include facilities providing different levels of care and facilities with different ownership structures (public, faith-based and private). The sample was drawn from across the country and included both rural and urban areas. This increased the likelihood of obtaining data that covered the full spectrum of PAC experiences. At the tertiary level of health care, 11 regional referral hospitals and 1 national referral hospital were selected. At the secondary level, 17 hospitals were canvassed: seven district hospitals, two private hospitals and eight faith-based hospitals. Ten primary-level facilities were also selected: three Health Center IIIs and seven Health Center IVs. Three health centres were private, operated by nurse-midwives and seven were public facilities.

All major regions of Uganda were covered with the exception of the north-east part of the country (Karamoja), which was avoided for security reasons. Otherwise, the physical accessibility of facilities was not a consideration in selecting the sample. The facilities are located in 29 of the 80 districts of
Uganda. $^{3}$ The survey respondents were experts who were knowledgeable about PAC in their facilities because of their many years of on-the-job experience. The respondents were requested to provide responses on the detailed inputs ${ }^{4}$ into PAC interventions that, in the aggregate, are needed to treat specific post-abortion complications. As the interviews were lengthy, interviewers were advised to split interviews into two or more sessions to minimize respondent fatigue.

A 2007 study by the Guttmacher Institute developed protocols for estimating the costs of unsafe abortion to the health system and to women and their households (Guttmacher Institute, unpublished data). The study instruments, consisting of two types of questionnaires, were tested in three countries, Ethiopia, Pakistan and Mexico. The health-system-cost component, now referred to as the 'Post-Abortion Care Costing Methodology' (PACCM), is a variant of the 'ingredients approach' (Johns et al. 2003; Weissman et al. 1999) and collects data from key informants. The method was first used in an exploratory study in Nigeria, which examined the cost of PAC (Bankole et al. 2007). It was also used in a costing study undertaken in Ethiopia in 2008 (Vlassoff et al. 2012). Our study builds on these previous efforts by applying the method to a study that includes facilities of all types, national coverage and estimates of both direct medical and non-medical costs of providing PAC.

The questionnaires administered to healthcare providers and facility managers collected detailed data on inputs needed for estimating the cost of PAC. These included information on personnel inputs of time, personnel wages, hospitalization costs, overhead costs and capital costs associated with the provision of PAC. Detailed data on the quantities of all drugs, supplies and materials used in specific post-abortion treatments were also collected. The averages of the estimates provided by the respondents are assumed to yield a good approximation of the true values of the various rates and amounts of specific inputs. Direct-cost data were gathered for each of five types of abortion complications-incomplete abortion, sepsis, shock, cervical/vaginal laceration and uterine laceration/perforation. ${ }^{5}$ This categorization was taken from the World Health Organization's classification concerning PAC (WHO 1999).

Respondents were queried on the time required to treat each type of abortion complication as well as time spent in non-treatment activities and the length of the work year, for each category of health worker involved. In gathering wage data, questions were asked on salary ranges, professional allowances, housing allowances, transportation allowances and duty fees. Some other benefits, such as medical workers' health insurance and communication allowance, were not estimated. Thus, personnel cost estimates in this study are likely to somewhat underestimate the true cost of labour. Data on labour costs were collected for 11 categories of health workers, for the five complication types and for the three levels of facilities. Costs of hospitalization per bed per day were also collected. ${ }^{6}$ Finally, in a section of the questionnaire on capital and overhead expenses, the respondents were asked to estimate the life of the equipment, capital costs for constructing new facilities, overhead costs and referral rates between facilities.

Questions on the drugs, supplies and materials used in the provision of treatments for specific post-abortion complications were directed at care providers with specific experience in this 
area. The list of drugs and supplies was based on evidence from previous studies in other countries, and the inputs listed in the World Health Organization's 'Mother-Baby Package' (WHO 1999).

Because the exact presentations, chemical strengths and packaging for all of the drugs and supplies used in PAC were not found in any centralized price list in Uganda, we used a mixture of local prices and, when local data were lacking, prices collected from a variety of international sources. We consulted various standard price lists (Durbin 2005; UNICEF 2005; IDA Foundation 2008; Management Sciences for Health 2008; Pharma Professional Services 2008; UNFPA 2009). When necessary, prices were extrapolated to 2010 by using World Bank Gross Domestic Product (GDP) deflators (World Bank 2010). The catalogue from the Joint Medical Store of Uganda provided local prices for more than half of the inputs (JMS 2012) and JMS prices were used, when available, in preference to international prices. ${ }^{7}$ Several factors that might influence the final price, in either direction, were not measured because of the time and cost of doing so. For example, spoilage, stocking costs and transportation costs, which would typically inflate final prices, were not included in the calculations. At the same time, discounts available through the centralized procurement of drugs and supplies, which would tend to decrease costs, were also excluded from the model. ${ }^{8}$

The annual capital $\operatorname{cost}^{9}$ for PAC for each type of facility was calculated as follows:

PacCost $=$ AmortAnnualCapitalCost/PacShare

where PacCost is the annual capital cost attributable to treating a single PAC case; AmortAnnualCapitalCost is the amortized cost per year of useful life ${ }^{10}$ and PacShare is the proportion of all cases treated by the facility that are related to post-abortion complications.

Data on quantities of inputs were collected according to what was typically needed for treating specific complications thus yielding estimates of 'costs per treatment'. As some patients may have more than one complication treated simultaneously, further calculations were performed to produce estimates of 'costs per case'. These unit costs are disaggregated by healthcare level, type of input, cost categories and type of complication. The same analysis is done to estimate total costs at the national level, which yields an estimate of the national health care bill due to unsafe abortion.

A sensitivity analysis is undertaken to gauge the degree to which errors in measuring different factors affect cost estimates. It also provides an interval estimate of costs. A subset of variables from the survey data was selected by inspection and cost estimates were calculated serially for maximum and minimum values of each variable. ${ }^{11}$

\section{Estimating the number of PAC cases}

Table 1 (top panel) shows inter alia estimates of how PAC cases were distributed across the levels of health facilities in the Uganda healthcare system based on facility records, and estimates made by respondents. Regional hospitals handled $\sim 10$ times more PAC cases annually than did general (district) hospitals, which in turn treated twice the number of cases as did primary level facilities. The estimates provided by survey respondents tended to be higher, indicating either that they suspected some under-reporting in the facility statistics, or that the number of PAC cases had increased since the statistics were last recorded. We use the caseload estimates from key informants in calculations of total national costs.

Only PAC cases associated with induced abortion were considered in this study-PAC cases from spontaneous abortions were not included. Two-thirds of PAC patients were treated for incomplete abortion, 22\% for sepsis and 9\% for shock. In general, serious complications, such as lacerations and perforations were more common at higher level facilities than lower level ones. Across all 39 facilities, each PAC patient was treated, on average, for 1.08 complications.

Table 1 also shows the numbers of cases of rare, but very serious complications. These include morbidities, such as peritonitis, renal failure, etc. The cost of treating these rare conditions is not estimated in this study, so the overall costs to be presented below are slightly under-estimated on that account.

The reported prevalence of PAC cases in the health system (e.g. PAC cases as a percent of all facility admissions) is also shown in Table 1. Two sources of information were available: the estimates of survey respondents and estimates available from the statistical records of the facilities. Table 1 shows averages, by facility type, from these two sources. ${ }^{12}$ Overall, we estimated that a little under $5 \%$ of all patients presenting at health facilities in Uganda in 2010 were admitted for PAC. ${ }^{13}$

A study of contraceptive needs in Uganda estimated that around 2.2 million pregnancies occurred in 2008 (Vlassoff et al. 2009a). Of these, $56 \%$ or $\sim 1.2$ million were unplanned pregnancies. An estimated 362000 of these unintended pregnancies resulted in induced abortions in 2008. ${ }^{14}$ Assuming that increases in the annual number of abortions were proportional to population growth, the number of induced abortions in 2010 would be $386000 .^{15}$ Of this group of women, the number who obtained care at health facilities for complications are shown in the bottom panel of Table 1. To arrive at these estimates, we used the number of PAC cases estimated in the 2003 abortion incidence study (Singh et al. 2005) and extrapolated them to $2010 .^{16}$ We then used the percentage distribution of PAC cases by type of facility in the 2003 incidence study to arrive at the estimates shown in the final panel of Table 1. For 2010, we estimated the total number of PAC cases in Uganda to be 105900.

Many women who have unsafe abortions and develop serious complications never reach a health facility. Information is scanty on how large this group of women is, but globally it has been estimated that there is around one such woman for every two PAC cases attended to by health facilities (Singh et al. 2009). Thus, in Uganda in 2010, women with 'untreated' abortion complications (at least untreated by the formal health system) may total more than 50000 women.

The 2010 survey showed that most PAC cases are treated as inpatients in Uganda. Computed over all complications and all facilities, only around $20 \%$ of PAC patients were outpatients, whereas $80 \%$ (not shown in Table 1) were inpatients. ${ }^{17}$ While hospitals treated only a small percentage of cases of incomplete abortion as outpatients, health centres reported substantial numbers of outpatients for cases of incomplete abortion, sepsis and lacerations. In many of these cases, minimal treatment was given, such as dispensing analgesics, and the patients were then referred to a higher-level facility. 
Table 1 Average number of PAC cases per year and distribution of abortion complications

\begin{tabular}{|c|c|c|c|c|}
\hline & $\begin{array}{l}\text { Regional } \\
\text { hospitals }\end{array}$ & $\begin{array}{l}\text { District } \\
\text { hospitals }\end{array}$ & $\begin{array}{l}\text { Health } \\
\text { centres }^{a}\end{array}$ & $\begin{array}{l}\text { All sampled } \\
\text { facilities }\end{array}$ \\
\hline \multicolumn{5}{|c|}{ Average number of PAC cases per year per facility } \\
\hline From facility records & 1534 & 154 & 79 & 560 \\
\hline Estimates of respondents & 1672 & 176 & 87 & 613 \\
\hline \multicolumn{5}{|c|}{ Percent of PAC cases with specific complications } \\
\hline Incomplete abortion & 62.1 & 67.4 & 71.3 & 66.7 \\
\hline Sepsis & 29.8 & 18.8 & 19.3 & 22.3 \\
\hline Shock & 12.5 & 10.0 & 4.5 & 9.4 \\
\hline Lacerations & 11.8 & 5.9 & 1.5 & 6.6 \\
\hline Perforations & 7.1 & 2.2 & 0.1 & 3.2 \\
\hline Total & 123.2 & 104.4 & 96.7 & 108.2 \\
\hline \multicolumn{5}{|c|}{ Number of PAC cases with rare complications ${ }^{\mathrm{b}}$} \\
\hline Number per 1000 PAC cases & 22 & 5 & 7 & 3 \\
\hline \multicolumn{5}{|c|}{ Percent of all admissions that are PAC cases ${ }^{c}$} \\
\hline Percent of all cases & 5.33 & 4.33 & 4.77 & 4.75 \\
\hline \multicolumn{5}{|c|}{ Percent of all admissions that are for $\mathrm{MNH}$ care } \\
\hline Percent of cases that are $\mathrm{MNH}$ & 51.3 & 41.8 & 37.5 & 43.6 \\
\hline \multicolumn{5}{|c|}{ Estimated number of PAC cases annually (2010) } \\
\hline Incomplete abortion & 3100 & 15200 & 55200 & 73500 \\
\hline Sepsis & 1500 & 4200 & 15200 & 20900 \\
\hline Shock & 600 & 2300 & 4000 & 6900 \\
\hline Lacerations & 600 & 1300 & 1600 & 3500 \\
\hline Perforations & 400 & 500 & 300 & 1200 \\
\hline All complications & 6100 & 23500 & 76200 & 105900 \\
\hline
\end{tabular}

${ }^{a}$ 'Health centres' include private midwives.

${ }^{\mathrm{b}}$ Rare complications include peritonitis, renal failure, organ failure, septicaemia, poisoning, heart failure, etc.

c'All admissions' means all patients that present at health facilities, both male and female.

\section{Limitations of the study}

The sample of facilities was purposive rather than random. This impeded the use of statistical probability analysis. However, we preferred to purposely select facilities where it was known that PAC caseloads would be substantial and where there would be respondents well versed in the details of post-abortion treatments. We reasoned that the variability in treatment standards and inputs used would not be large among facilities of the same type. For scaling estimates up to the national level we relied on data from the 2003 abortion incidence survey, which was based on random sampling. Thus, we assume that the conditions of abortion provision have remained the same over the intervening period.

The PACCM approach relies on expert opinion and estimates. The methodology is a low-cost one meant to generate reliable cost estimates where a certain amount of precision is traded off against the cost of collecting data. The validity of the data rests on the long experience in providing PAC of the professionals interviewed.

Certain inputs were also difficult or impossible to measure with high precision. The future rate of inflation, for instance, cannot be known: we followed the usual practice of assuming a constant rate of $3 \%$ per year. Drugs come in a sometimes bewildering variety of presentations. We adopted an averaging approach when confronted with a variety of options in presentation, packaging, bundling, strength, etc. Determining the price of labour is similarly imprecise at the margin: although we accounted for the main components of wages, several particular benefits and compensations were not taken into account due to their complexity, implying that labour costs are thus slightly underestimated.

\section{Results}

\section{Direct medical costs}

\section{Costs of drugs and supplies}

Costs per case of drugs and supplies increased with the level of care, from $\sim \$ 22$ in health centres to $\$ 41$ in regional hospitals (Table 2). ${ }^{18}$ This relationship was expected since more severe complications tend to be treated in higher level facilities. Lower-level facilities, lacking the required personnel, supplies and infrastructure, are more likely to refer critical patients to higher level facilities. ${ }^{19}$ The costs of drugs and supplies for outpatients were also found to be dramatically lower than for inpatient costs (not shown in table). This is consistent with the practice in Uganda of treating all but the least severe complications as inpatients. The costs of drugs, supplies and other materials used in treating cases of shock, sepsis, incomplete abortion and lacerations were remarkably similar, varying between \$23 and \$28 per intervention across all patients (Table 2, bottom panel). For treatment of uterine perforations, 
the average per-intervention cost of drugs and supplies was far higher at $\$ 81$.

The main drivers of costs in the category of drugs and supplies, which included laboratory tests, varied according to type of treatment. In treating incomplete abortion, for instance, the principal drivers were procedures, such as ultrasound and blood tests, sterilized gloves and some expensive drugs, such as ceftriaxon and metronidazole. In treating uterine perforations, on the other hand, operating room supplies, such as surgical drapes, gloves, anaesthetic drugs and special needle holders were the major cost drivers.

Medicines and supplies were the costliest direct inputs used in treatment, accounting overall for $58 \%$ of direct treatment costs (Table 2, middle panel). In health centres drugs, supplies and other materials amounted to $62 \%$ of all direct medical costs.

\section{Costs of personnel}

The proportions of cases seen by health workers and the time spent treating patients are two of the main factors in determining personnel costs. The proportion of patients seen by health personnel varied considerably by type of facility and by cadre (not shown in Table 2). For example, in regional hospitals only $18 \%$ of patients suffering from incomplete abortion were attended to by anaesthetists, but $97 \%$ of these patients saw midwives and $92 \%$ saw drug dispensers in the facilities. On the other hand, all the patients receiving treatment for perforations were attended to by anaesthetists, but only $33 \%$ by nursing assistants. The average number of minutes that health workers spent attending patients also varied considerably by category of worker and by type of complication. For instance, at district hospitals general practitioners and gynaecologists spent 53-71 min with patients suffering from hypovolaemic shock, whereas nurses and midwives spent 113-136 min (not shown in table).

The average cost of labour per case was $\$ 15$ at district hospitals and regional hospitals, and $\$ 10$ at health centres (Table 2, top panel). This difference reflected the greater severity of the cases treated at hospitals and the more costly make up of the care givers. Nonetheless, the proportion of direct medical costs spent in labour inputs varied little by facility type, from $25 \%$ for regional hospitals to $28 \%$ for health centres.

The cost of labour per PAC intervention varied by complication (Table 2, bottom panel). Treating lacerations and incomplete abortions had the lowest average cost of labour $(\$ 12-\$ 13)$. The cost of labour for treating sepsis and shock ranged from $\$ 15$ to $\$ 16$ and the labour cost for repairing a perforated uterus was the most expensive in terms of labour input, amounting to $\$ 26$.

\section{Other direct medical costs}

Data were also collected on two other direct costs: hospitalization costs and outpatient special fees. As seen in Table 2, hospitalization (accommodation and meals only) was an important component of cost, comprising $7-19 \%$ of total direct medical costs. District hospitals had considerably higher hospitalization costs per PAC case $(\$ 11)$ than did regional hospitals $(\$ 5.40)$ or health centres $(\$ 2.50) .{ }^{20}$ In the bottom panel of Table 2, we see that cases of sepsis on average incurred the highest cost of hospitalization (\$11), followed by treatment of perforations $(\$ 7.50)$.

The average length of stay (not shown in Table 2) varied-as expected-by both type of facility and treatment. Post-abortion cases spent an average of 3.8 days in regional referral hospitals but only 1.6 days in health centres. In regional hospitals, patients being treated for incomplete abortion stayed, on

Table 2 Cost per case for PAC by facility type and cost per treatment by type of complication (USD 2010)

\begin{tabular}{|c|c|c|c|c|c|}
\hline & \multicolumn{5}{|l|}{ Facility level } \\
\hline & Regional hospitals & District hospitals & Health centres & \multicolumn{2}{|c|}{ All sampled facilities } \\
\hline \multicolumn{6}{|l|}{ Components of cost per case } \\
\hline Inputs of drugs, supplies and materials & 41.48 & 29.59 & 21.92 & \multicolumn{2}{|l|}{24.18} \\
\hline Inputs of labour & 15.22 & 14.93 & 9.88 & \multicolumn{2}{|l|}{11.16} \\
\hline Hospitalization & 5.37 & 10.57 & 2.54 & \multicolumn{2}{|l|}{5.61} \\
\hline Special outpatient fees & 0.10 & 0.70 & 0.99 & \multicolumn{2}{|l|}{0.47} \\
\hline Total direct medical costs & 62.17 & 55.78 & 35.33 & \multicolumn{2}{|l|}{41.43} \\
\hline \multicolumn{6}{|l|}{ Percentage distribution of costs } \\
\hline Inputs of drugs, supplies and materials & 66.7 & 53.0 & 62.0 & \multicolumn{2}{|l|}{58.4} \\
\hline Inputs of labour & 24.5 & 26.8 & 28.0 & \multicolumn{2}{|l|}{26.9} \\
\hline Hospitalization & 8.6 & 19.0 & 7.2 & \multicolumn{2}{|l|}{13.5} \\
\hline Special outpatient fees & 0.2 & 1.2 & 2.8 & \multicolumn{2}{|l|}{1.1} \\
\hline \multirow[t]{3}{*}{ Total direct medical costs } & 100.0 & 100.0 & 100.0 & \multicolumn{2}{|l|}{100.0} \\
\hline & \multicolumn{2}{|c|}{ Type of complication } & & & \\
\hline & Incomplete abortion & Sepsis & Shock & Lacerations & Perforations \\
\hline \multicolumn{6}{|l|}{ Components of cost per treatment } \\
\hline Inputs of drugs, supplies and materials & 27.63 & 23.32 & 25.51 & 32.32 & 81.34 \\
\hline Inputs of labour & 11.67 & 14.71 & 16.07 & 12.79 & 26.05 \\
\hline Hospitalization & 3.43 & 10.56 & 6.89 & 4.34 & 7.49 \\
\hline
\end{tabular}


average, for 1.4 days, whereas women suffering uterine perforations remained hospitalized for an average of 7.3 days.

Outpatients often paid special fees to receive treatment. $^{21}$ These are also shown in the top panel of Table 2. The estimated average fees ${ }^{22}$ for outpatients, ranging from $\$ 0.10$ to $\$ 0.99$, were not found to be an important driver of PAC costs. Nevertheless, it is worth noting that, while special outpatient fees comprised only $1 \%$ of the total cost per case, they amounted to around 3\% of the total for health centres where most outpatient care is concentrated.

\section{Direct non-medical costs}

Very few costing studies of PAC have attempted to compute direct non-medical costs (Vlassoff et al. 2008). These costs are, however, an important component of total costs. In the United Nations, global estimates of reproductive health costs, for instance, direct non-medical $\operatorname{costs}^{23}$ are estimated at roughly twice the magnitude of direct medical costs in sub-Saharan Africa (United Nations 2009). In other studies, one quarter to one-third of total PAC costs have been estimated to be non-medical (Vlassoff et al. 2008). This study is the first thoroughgoing attempt to measure the direct non-medical costs to the health system with regard to PAC.

Table 3 shows results for both overhead and capital costs. The survey collected overhead costs in two broad categories: the cost of ancillary workers in the health system; and maintenance and other operational costs. The details of what comprised these two categories are given in notes to Table 3. In 2010, the total annual wage bill for ancillary workers per facility was $\sim \$ 41000$ across all health facilities sampled, ranging from $\$ 64000$ for large hospitals to around $\$ 11000$ for health centres. On average, our study showed that regional referral hospitals employed 43 workers, district hospitals 28 workers and health centres 9 workers for ancillary, non-care tasks. The average annual maintenance and operating cost per facility was $\$ 53000$ (ranging from $\$ 13000$ to $\$ 124000$ ). Thus, the total average overhead cost per sample facility amounted to $\$ 94000$ per annum and the portion of that total attributable to the care of post-abortion patients was $\$ 4500$ per facility- $\$ 10000$ for regional hospitals, $\$ 2800$ for district hospitals and $\$ 1100$ for health centres. Interestingly, however, the average overhead cost 'per PAC case' varied relatively little due to the distribution of PAC cases by level of care. Thus, on average $\$ 20$ of overhead expense went into the treatment of one PAC case at regional hospitals and health centres, whereas \$16 was spent at district hospitals. At every level, overhead costs were a significant component of the total cost of PAC to the health system.

Capital cost estimates are shown in the lower panel of Table 3. Overall estimates of capital costs for the infrastructure and equipment of the facilities were obtained from the key informants. Estimates of actual facility lifetimes (total years of use) were also asked for in the survey. Regional hospitals were estimated to cost $\$ 43$ million on average to construct and equip, while health centres cost $\$ 1.3$ million. At the same time, respondents reported that facilities were used for several decades before being replaced by new infrastructure, ranging from 68 years for regional hospitals to 33 years for health centres.

Using the case of health centres as an example, the proportion of the annual amortized cost attributable to PAC was $\$ 3100$ and the annual capital cost per PAC case was $\$ 55 .^{24}$ The cost of capital was greatest for regional hospitals at $\$ 158$ per PAC case compared with $\$ 98$ at district hospitals.

Table 3 Overhead and capital components of PAC cost per case by facility type (USD 2010)

\begin{tabular}{|c|c|c|c|c|}
\hline & $\begin{array}{l}\text { Regional } \\
\text { hospitals }\end{array}$ & $\begin{array}{l}\text { District } \\
\text { hospitals }\end{array}$ & $\begin{array}{l}\text { Health } \\
\text { centres }\end{array}$ & $\begin{array}{l}\text { All sampled } \\
\text { facilities }\end{array}$ \\
\hline \multicolumn{5}{|l|}{ Overhead costs } \\
\hline Total annual wage bill for ancillary workers per facility ${ }^{\mathrm{a}}$ & 64000 & 42000 & 11000 & 41000 \\
\hline Total maintenance and other costs ${ }^{\mathrm{b}}$ & 124000 & 23000 & 13000 & 53000 \\
\hline Total annual overhead cost per facility & 188000 & 65000 & 24000 & 94000 \\
\hline Total annual overhead cost to supply PAC per facility & 10000 & 2800 & 1100 & 4500 \\
\hline Overhead cost per PAC case & 19.57 & 15.77 & 19.80 & 18.89 \\
\hline \multicolumn{5}{|l|}{ Capital costs } \\
\hline \multicolumn{5}{|l|}{ Construction and equipment costs per facility } \\
\hline Amount per facility & 43090000 & 9830000 & 1330000 & 17880000 \\
\hline \multicolumn{5}{|l|}{ Useful lifetime } \\
\hline Number of years & 68 & 45 & 33 & 49 \\
\hline \multicolumn{5}{|c|}{ Amortized annual construction and equipment costs to supply $\mathrm{PAC}^{\mathrm{C}}$} \\
\hline Amount per facility & 80500 & 17500 & 3100 & 33800 \\
\hline Capital cost per PAC case & 157.59 & 98.38 & 55.47 & 70.91 \\
\hline
\end{tabular}

${ }^{a}$ Data collected on the following non-medical personnel: guard, cleaner, receptionist, record keeper, supply clerk, maintenance worker, driver, food preparer, health inspector, assistant health inspector, health educator and assistant health educator.

${ }^{b}$ Data were collected on the following items: building maintenance, utilities, vehicle maintenance, travel expenses, audio/visual materials, education/reference materials and printed materials.

${ }^{\mathrm{c}}$ The future annual rate of inflation is assumed to be $3 \%$. 


\section{Discussion}

\section{Total costs per case}

The total direct costs of all inputs per PAC case, both medical and non-medical, by facility type across all types of complications are shown in Table 4. The overall cost per PAC case was estimated to be \$131. Treatment of post-abortion cases at regional hospitals cost $\$ 239$ on average, while \$111 was spent on average at health centres. The direct medical cost per case$\$ 41$ overall-was closely related to the level of care. Regional hospitals expended $\$ 62$ on direct inputs to treatment, district hospitals \$56 and health centres \$35 (Table 4).

Overall, $\sim 68 \%$ of the total direct cost of PAC was nonmedical-expenditures in capital and overhead that were not directly tied to the provision of care but which were necessary for the health system to be able to provide care services at all. The non-medical component of costs at regional hospitals was $74 \%$ of the total, but $67-68 \%$ of total costs were non-medical at district hospitals and health centres. More than three quarters of direct non-medical costs were capital costs (\$71), while the remainder (\$19) was overhead costs expended on general maintenance and infrastructure operations.

\section{National cost of PAC}

Using estimates of costs per case and cost per treatment, national total annual costs for treating post-abortion complications in Uganda were calculated for 2010. These are shown in Table 5, which breaks down total costs by care level, by abortion complication (where applicable) and by cost component. The total cost to the Uganda health system for treating PAC in 2010, including direct medical and non-medical costs, was estimated to be $\$ 13.9$ million (bottom panel). ${ }^{25}$ Two-thirds of this amount, or $\$ 9.5$ million, went to non-medical costs (overhead and infrastructure) and the remaining third (\$4.4 million) was spent on direct medical inputs (drugs, supplies, labour, hospitalization and outpatient fees). Hospitalization accounted for $3.4 \%$ of total expenditure, drugs and supplies for $18.9 \%$ and the wage bill for $8.6 \%$.

Table 4 Cost per case for PAC by facility type (USD 2010)

\begin{tabular}{|c|c|c|c|c|}
\hline \multirow[t]{2}{*}{ Components of cost } & \multicolumn{4}{|c|}{ Facility level } \\
\hline & $\begin{array}{l}\text { Regional } \\
\text { hospitals }\end{array}$ & $\begin{array}{l}\text { District } \\
\text { hospitals }\end{array}$ & $\begin{array}{l}\text { Health } \\
\text { centres }\end{array}$ & $\begin{array}{l}\text { All } \\
\text { sampled } \\
\text { facilities }\end{array}$ \\
\hline Direct medical costs ${ }^{a}$ & 62.17 & 55.78 & 35.33 & 41.43 \\
\hline \multicolumn{5}{|l|}{ Direct non-medical costs ${ }^{b}$} \\
\hline Overhead & 19.57 & 15.77 & 19.80 & 18.89 \\
\hline Capital & 157.59 & 98.38 & 55.47 & 70.91 \\
\hline Total non-medical costs & 177.16 & 114.14 & 75.26 & 89.80 \\
\hline Total cost per PAC case & 239.32 & 169.93 & 110.59 & 131.23 \\
\hline \multicolumn{5}{|l|}{ Percentage distribution } \\
\hline Medical costs & 26.0 & 32.8 & 31.9 & 31.6 \\
\hline Non-medical costs & 74.0 & 67.2 & 68.1 & 68.4 \\
\hline Total direct cost per PAC case & 100.0 & 100.0 & 100.0 & 100.0 \\
\hline
\end{tabular}

${ }^{\mathrm{a}}$ From Table 2.

${ }^{\mathrm{b}}$ From Table 3.
As can be seen in the three upper panels of Table 5, incomplete abortion was by far the costliest PAC complication, comprising more than three-fifths of total direct medical costs. Sepsis accounted for one-fifth of such expenditure, while lacerations and perforations each consumed only around $3-6 \%$ of direct medical inputs. In terms of level of care, most PAC expenditure was concentrated in health centres $(\$ 8.4$ million or $61 \%$ ), followed by district hospitals ( $\$ 4.0$ million or $29 \%$ ) and then by regional hospitals ( $\$ 1.5$ million or $11 \%$ ).

\section{Sensitivity analysis}

Since the data collected in this study were largely based on best estimates of key experts, we undertook a sensitivity analysis. Given that data on several hundred inputs were collected in the study, an inspection of the data set was made to narrow down consideration to a subset of variables likely to have the largest effect on the overall cost-per-case estimate. Twenty-three such variables were selected spanning all major components of PAC costs.

The central estimate of the national cost for PAC treatment in 2010, as shown in Table 5, was $\$ 13.9$ million. The variable to which this estimate was the most sensitive was the capital cost of infrastructure and equipment of health facilities: the total cost ranged from $\$ 12.0$ to $\$ 15.8$ million when this variable was set at its minimum or its maximum value. However, total cost was insensitive to most of the selected variables. For example, the estimated time doctors spent in treating cases of incomplete abortion, when set at the minimum and maximum values, changed the total cost of PAC by only $\sim \$ 0.03$ million $(\$ 30000$ ) above or below the mean value.

When all 23 variables were set to their minimum values, the overall national cost decreased to $\$ 9.9$ million, while when all assumed their maximum values it increased to $\$ 22.2$ million. ${ }^{26}$ While it is extremely improbable that the true values of all the variables would lie in the same direction (i.e. all either below their means or all above them), this range may be thought of as a confidence interval within which the true overall cost most likely lies. ${ }^{27}$

The relative sensitivity of the 23 selected variables is displayed in Table 6. The first column shows the ratio of the overall cost, calculated at the minimum value of a particular variable, to the cost calculated using the variable's mean value. The second column shows similar ratios using maximum values. The third column shows the arithmetic difference between these two sets of ratios. For example, the eighth variable, the cost of hospitalization per night, yielded an total cost $\sim 0.9 \%$ less or $0.9 \%$ more than the central estimate when minimum or maximum values were substituted for the mean value, and the spread was, thus, 1.7 percentage points. The variables in Table 6 are listed in order of the relative sensitivity of cost estimates to changes in their value. Thus, the proportion of all patients who are PAC cases was the most sensitive variable, followed by the estimated cost of a facility's infrastructure and equipment, the presumed future rate of inflation, the estimated useful lifetime of infrastructure and non-wage overhead costs. This highlights the importance of giving non-medical cost data greater prominence in the design of future studies of PAC costs. Fourteen of the other variables examined had a spread of one percentage point or less. Moreover, the estimate of total cost was virtually insensitive to changes in the last 10 variables listed in the table. 
Table 5 Estimates of total costs at the national level of PAC by facility level and type of complication (USD 2010)

\begin{tabular}{|c|c|c|c|c|c|}
\hline Cost components & $\begin{array}{l}\text { Regional } \\
\text { hospitals }\end{array}$ & $\begin{array}{l}\text { District } \\
\text { hospitals }\end{array}$ & $\begin{array}{l}\text { Health } \\
\text { centres }\end{array}$ & $\begin{array}{l}\text { All } \\
\text { facilities }\end{array}$ & $\begin{array}{l}\text { Percentages } \\
\text { across } \\
\text { components }\end{array}$ \\
\hline \multicolumn{6}{|l|}{ National cost of labour for PAC } \\
\hline Incomplete abortion & 47000 & 227000 & 555000 & 739000 & \\
\hline Sepsis & 23000 & 63000 & 150000 & 247000 & \\
\hline Shock & 9000 & 34000 & 35000 & 104000 & \\
\hline Lacerations & 9000 & 20000 & 12000 & 73000 & \\
\hline Perforations & 5000 & 8000 & 1000 & 35000 & \\
\hline All complications & 93000 & 351000 & 753000 & 1197000 & 8.6 \\
\hline \multicolumn{6}{|c|}{ National cost of drugs, supplies and materials for PAC } \\
\hline Incomplete abortion & 128000 & 449000 & 1232000 & 1617000 & \\
\hline Sepsis & 61000 & 126000 & 334000 & 541000 & \\
\hline Shock & 26000 & 67000 & 78000 & 227000 & \\
\hline Lacerations & 24000 & 40000 & 26000 & 160000 & \\
\hline Perforations & 15000 & 15000 & 2000 & 77000 & \\
\hline All complications & 254000 & 696000 & 1671000 & 2621000 & 18.9 \\
\hline \multicolumn{6}{|l|}{ National cost of hospitalization for PAC } \\
\hline Incomplete abortion & 17000 & 161000 & 143000 & 293000 & \\
\hline Sepsis & 8000 & 45000 & 39000 & 98000 & \\
\hline Shock & 3000 & 24000 & 9000 & 41000 & \\
\hline Lacerations & 3000 & 14000 & 3000 & 29000 & \\
\hline Perforations & 2000 & 5000 & 0 & 14000 & \\
\hline All complications & 33000 & 249000 & 194000 & 476000 & 3.4 \\
\hline \multicolumn{6}{|c|}{ National cost of outpatient 'special fees' for PAC } \\
\hline National cost for all outpatients & 1000 & 16000 & 75000 & 92000 & 0.7 \\
\hline \multicolumn{6}{|c|}{ Amortized annual construction and equipment costs to supply PAC } \\
\hline Capital cost to system to supply PAC & 965000 & 2314000 & 4228000 & 7508000 & 54.0 \\
\hline \multicolumn{6}{|l|}{ National overhead costs for PAC } \\
\hline Overhead cost per PAC case & 120000 & 371000 & 1509000 & 2000000 & 14.4 \\
\hline Total costs of PAC & 1466000 & 3997000 & 8430000 & 13894000 & 100.0 \\
\hline Total direct medical costs of PAC & 381000 & 1312000 & 2693000 & 4386000 & 31.6 \\
\hline Total direct non-medical costs of PAC & 1085000 & 2685000 & 5737000 & 9508000 & 68.4 \\
\hline
\end{tabular}

\section{Conclusion and implications}

We estimate that the cost of treating post-abortion complications in Uganda in 2010 stood at \$13.9 million. Given that the data from the survey are largely based on key informants, we subjected the data to a sensitivity analysis, which showed that the total cost of unsafe abortion to the Ugandan health system most likely lies in the range of \$9.9-\$22.2 million.

Total expenditure on health in Uganda in 2010 is reported to be $\$ 1.56$ billion and, of that, the amount spent by the government of Uganda was roughly $\$ 340$ million (WHO 2011). The total amount spent in Uganda on maternal and newborn health-in both public and private sectors-was estimated at around \$350 million (Vlassoff et al. 2009a). Thus, our estimates indicate that the cost of treating post-abortion complications from unsafe abortion procedures may be around $4.0 \%$ of total spending on maternal and newborn health and equivalent to $4.1 \%$ of total government spending on health. The cost of unsafe abortion to the health system is, therefore, a substantial one.
Although evidence is very limited, surveys of key informants show that a large proportion of women suffering abortion complications never access services through the formal health system (Singh et al. 2005). Globally, it has been estimated that the number of such women is around $50 \%$ of the number who do reach health facilities (Singh et al. 2009). This implies that the total cost of PAC in 2010 would have amounted to $\$ 20.8$ million if all women with complications had been able and willing to access facility-based care. We must bear in mind, however, that this estimate is based on expert opinion, not population-based data, and also that women not attending health facilities may have less severe symptoms on average than those who do. Despite this uncertainty, there is no doubt that treating all women who have an unmet demand for PAC would pose a significant additional cost on the health system in Uganda. Improvement of the health system is, therefore, a priority if Uganda is to meet the post-abortion needs of its women. 
Table 6 Sensitivity analysis: relative effects on total national cost of variations in 23 selected variables

\begin{tabular}{|c|c|c|c|}
\hline Selected variable & $\begin{array}{l}\text { Ratio of costs: } \\
\text { minimum value } \\
\text { vs mean value }\end{array}$ & $\begin{array}{l}\text { Ratio of costs: } \\
\text { maximum value } \\
\text { vs mean value }\end{array}$ & $\begin{array}{l}\text { Spread between } \\
\text { minimum value } \\
\text { and maximum value }\end{array}$ \\
\hline PAC share & 0.826 & 1.174 & 0.347 \\
\hline Infrastructure + equipment & 0.863 & 1.137 & 0.274 \\
\hline Inflation rate & 0.911 & 1.099 & 0.187 \\
\hline Lifetime of infrastructure & 0.945 & 1.090 & 0.146 \\
\hline Other overhead costs & 0.981 & 1.019 & 0.038 \\
\hline Annual wage bill, non-medical personnel & 0.982 & 1.018 & 0.035 \\
\hline Proportion incomplete abortion & 0.977 & 1.000 & 0.023 \\
\hline Cost per night & 0.991 & 1.009 & 0.017 \\
\hline Proportion outpatients, incomplete abortion & 0.994 & 1.006 & 0.012 \\
\hline Midwife hours for treatment of incomplete abortion & 0.996 & 1.004 & 0.007 \\
\hline Average length of stay, sepsis & 0.997 & 1.003 & 0.007 \\
\hline Percent hospitalized, sepsis & 0.997 & 1.003 & 0.007 \\
\hline Doctor hours for treatment of incomplete abortion & 0.997 & 1.003 & 0.006 \\
\hline Proportion sepsis & 1.000 & 1.005 & 0.005 \\
\hline $\mathrm{Ob} / \mathrm{gyn}$ hours for treatment of incomplete abortion & 0.998 & 1.002 & 0.004 \\
\hline Nurse hours for treatment of incomplete abortion & 0.998 & 1.002 & 0.004 \\
\hline Average length of stay, incomplete abortion & 0.999 & 1.001 & 0.003 \\
\hline Percent hospitalized, incomplete abortion & 0.999 & 1.001 & 0.003 \\
\hline Doctor hours for treatment of sepsis & 0.999 & 1.001 & 0.002 \\
\hline Ob/gyn hours for treatment of sepsis & 0.999 & 1.001 & 0.002 \\
\hline Midwife hours for treatment of sepsis & 0.999 & 1.001 & 0.002 \\
\hline Nurse hours for treatment of sepsis & 1.000 & 1.000 & 0.001 \\
\hline Proportion outpatients, sepsis & 1.000 & 1.000 & 0.001 \\
\hline All 23 variables & 0.712 & 1.596 & 0.883 \\
\hline
\end{tabular}

It needs to be emphasized that this study looks at only one element of the cost of unsafe abortions - the immediate cost to the health system of treating post-abortion complications. There are many other substantial costs involved (Vlassoff et al. 2008) including the treatment of longer-term morbidities that result from unsafe abortion-especially the high cost of infertility treatment-as well as the economic cost to Ugandan households and society of productive time lost through abortionrelated morbidity and mortality.

Ultimately, better health policy should be aimed at preventing the root cause of unsafe abortion in Uganda-namely the large number of unintended pregnancies. About 1.2 million unintended pregnancies occur every year in Uganda, largely due to unmet need for contraception (Vlassoff et al. 2009a). A cost-benefit analysis in Nigeria showed that extra spending on family planning would lead to large net benefits (savings) from reduced expenditure in PAC services (Bankole et al. 2007). A similar argument can be made here. The cost of supplying the methods of contraception most widely used in Uganda for 1 year has been estimated at around \$22 per user (Vlassoff et al. 2009a). If we compare this to the overall cost-per-case for treating post-abortion complications $(\$ 131)$ we can see that there is a large cost-benefit advantage to preventing unwanted pregnancies in Uganda. The benefit-cost ratio of adopting such a strategy would be almost 6:1; i.e. every dollar spent in family planning would save more than five dollars in PAC services averted.

In Uganda, legal abortion remains highly restricted and unmet demand for contraception is high. To promote policy discussion in this area, there is a clear need for the research into the economic effects resulting from illegal, unsafe abortion. The findings from this study should be interesting for scholars, policy makers and advocates who are striving to reduce the health and economic costs of unsafe abortion. The cost estimates from this study are useful to guide discussions on how to prevent and treat post-abortion complications in a country where abortion is restricted.

\section{Supplementary Data}

Supplementary data are available at HEAPOL online.

\section{Funding}

This work was supported by the Swedish International Development Agency; the Netherlands Ministry of Foreign Affairs; and the David and Lucile Packard Foundation.

Conflict of interest statement. None declared. 


\section{Endnotes}

${ }^{1}$ We use the term 'direct medical costs' to refer to inputs directly related to the provision of medical care and 'direct non-medical costs' to refer to health-system costs not related to actual treatment, such as overhead and capital costs.

2 Another study of the costs of unsafe abortion to women and households (the societal perspective) is being undertaken in conjunction with the study reported here and will report its findings in the near future.

${ }^{3}$ New districts are frequently carved out of existing districts in Uganda, so the total number of districts changes often.

4 'Input' ('ingredient') is used here to mean any physical thing that is used in the provision of a particular treatment. Aspirin tablets, syringes, sterile gloves, minutes spent by health workers and sonograms are all examples of inputs.

5 The category 'uterine perforation' also includes cases of other lower abdominal perforations and hysterectomies.

${ }^{6}$ To avoid double counting, only the 'hotel' components of the cost of hospitalization are used in the analysis. These components include accommodation and meals.

7 In practice, the two sets of prices were quite comparable: of 51 overlapping inputs, 26 JMS prices were lower than international ones and 25 were higher.

8 Foreign donors may sometimes procure drugs and supplies free of charge to developing countries. We do not take such contingencies into account since we are concerned in this paper with how much PAC costs, not with who pays for it.

${ }^{9}$ Capital costs comprised the cost of construction of the facility and the complete equipping of it, including furniture, vehicles and specialized machines and equipment, such as X-ray machines, laboratory equipment, etc. Facilities often had records of construction costs that could be consulted.

${ }^{10}$ Amortization was calculated as follows. If a constant rate of inflation is assumed, then the annual write off or depreciation of capital should take this into account. The annual depreciation amount should be adjusted upwards so that the present value of all such amounts is equal the amount of the original investment. Here, we assume an annual rate of inflation of 3\%. 'Useful' lifetime means the number of years a facility is actually in use for the purpose for which it was intended until it needs to be replaced.

${ }^{11}$ For most variables, the minimum was $75 \%$ of the variable's central estimate and the maximum was $125 \%$ of the central estimate.

12 The Ministry of Health, Uganda $(\mathrm{MOH})$ estimates were higher than those of the experts. A further data source available for estimating the share of PAC cases in the system's total caseload is $\mathrm{MOH}$ statistics on the distribution of maternal-health cases, including PAC cases, for the period 2005-8. Combining these MOH statistics with estimates of the proportion of all cases that are maternal and newborn cases, which we obtained from our study, we get an estimate of the share of PAC in the system's total caseload considerably higher than the estimates noted earlier. In our analysis we chose to use the more conservative estimates shown in Table 1.

13 These percentages are used to estimate the proportions of overhead and capital costs to assign to PAC.

14 This number is an extrapolation from the original 2003 estimate of induced abortions. See Singh et al. (2005).

15 The annual population growth rate over the period 2003-10 in Uganda was $3.23 \%$ (UN Population Division, online data, accessed 22 November 2011).

${ }^{16}$ Although our survey collected data on the number of PAC cases, we decided to use estimates from the 2003 survey as our survey was not a probabilistic one. The 2003 facility-based treatment rate per 1000 women of reproductive age was applied to women of reproductive age in 2010, assuming that the rate remained the same over this period of time.

${ }^{17}$ However, being a PAC inpatient in Uganda does not necessarily imply staying in the facility overnight: many inpatients are discharged the same day as they are treated after spending several hours recuperating in the facility.

18 All costs in this study are given in 2010 US dollars (USD).
${ }^{19}$ Other effects may also be influencing this relationship: higher level facilities may have better access to a wider range of drugs, technology and equipment and may therefore expend more inputs than lower level facilities.

${ }^{20}$ The reported per-day fee of hospitalization is the factor that elevated the cost at district hospitals compared with other facilities. The average fee charged at district hospitals was almost three times the fee at regional hospitals. The fee at health centres was almost twice that of regional hospitals. A possible explanation for this seemingly counter-intuitive finding is that the informal charging of user fees (see below) may be more prevalent in rural settings than in urban ones.

21 User fees were abolished at primary care public facilities in 2001 (Xu et al. 2005). In practice, however, the collection of user fees has continued informally in several facilities.

22 Special fees include unofficial fees for service and any special fees such as a fee for use of the operating theatre. They do not include the costs of drugs or supplies which the patients may have to buy separately.

23 Indirect costs are also called 'programme and system costs' and comprise overhead costs for programme management, supervision, health education, monitoring and evaluation, advocacy, human resources training, information systems, commodity supply systems and capital costs for maintaining and expanding the physical capacity of health facilities (United Nations 2009).

24 As an example of how inflation assumptions affect this estimate, with inflation at $0 \%$, the cost per PAC case at health centres would fall to $\$ 34$; with inflation at $4 \%$, the annual cost would rise to $\$ 642$.

25 In comparison, using African regional estimates of PAC costs from Vlassoff et al. (2009b) and the Ugandan share of the population of Africa, we would calculate a PAC cost per case of $\$ 16.8$ million (2010 USD), including both direct and indirect costs.

${ }^{26}$ The size of this range of estimates is largely accounted for by the sensitivity of cost estimates to a few of the indirect cost variables as shown in Table 6. The range of estimates for direct costs is much narrower, between $\$ 3.9$ and $\$ 5.1$ million.

27 All the other variables left out of the sensitivity analysis would contribute very little to the variation of the cost estimate even if they were included.

\section{References}

Babigumira JB, Stergachis A, Veenstra DL et al. 2011. Estimating the costs of induced abortion in Uganda: a model-based analysis. BMC Public Health 11: 904.

Bankole A, Singh S, Vlassoff M, Woog V. 2007. Estimating the cost of post-abortion care in Nigeria: a case study. In: Lule E, Singh S, Chowdhury SA (eds). Fertility Regulation Behaviors and Their Costs. Washington DC: World Bank, pp. 65-92.

Durbin PLC. 2005. Price List. www.durbin.co.uk, accessed 15 July 2009.

Henshaw SK, Adewole I, Singh S et al. 2008. Severity and cost of unsafe abortion complications treated in Nigerian hospitals. International Family Planning Perspectives 34: 40-50.

IDA Foundation. 2008. IDA Foundation E-Catalogue and Order Form. www. idafoundation.org/we-offer/web-catalogue.html, accessed 15 July 2009.

Johns B, Baltussen R, Hutubessy R. 2003. Programme costs in the economic evaluation of health interventions. Cost Effectiveness and Resource Allocation 1: 1.

Johnston HB, Gallo MF, Benson J. 2007. Reducing the costs to health systems of unsafe abortion: a comparison of four strategies. Journal of Family Planning and Reproductive Healthcare 33: 250-7.

Joint Medical Store (JMS). 2012. Price Catalogue. Kampala, Uganda: JMS. http://www.jms.co.ug/uploads/catalogue.pdf, accessed on 1 September 2012.

Levin A, Dmytraczenko T, McEuen M, Ssengooba F, Mangani R, Van Dyck G. 2003. Costs of maternal health care services in three 
anglophone African countries. International Journal of Health Planning and Management 18: 3-22.

Management Sciences for Health. 2008. International Drug Price Indicator Guide. $\quad$ http://erc.msh.org/mainpage.cfm?file=1.0.htm\&module= DMP\&language=English, accessed 15 July 2009.

Prada E, Mirembe F, Ahmed FH, Nalwadda R, Kiggundu C. 2005. Abortion and Postabortion Care in Uganda: A Report from Health Care Professionals and Health Facilities. Occasional Report No. 17. New York: Guttmacher Institute.

Pharma Professional Services. 2008. www.phaps.com, accessed 15 July 2009.

Singh S, Prada E, Mirembe F, Kiggundu C. 2005. The incidence of induced abortion in Uganda. International Family Planning Perspectives 31: 183-91.

Singh S, Wulf D, Hussain R, Bankole A, Sedgh G. 2009. Abortion Worldwide: A Decade of Uneven Progress. New York: Guttmacher Institute.

UNICEF. 2005. Supplies and Logistics. https://supply.unicef.org/unicef_b2c/ app/displayApp/\%28layout $=7.0-12 \quad 1 \quad 66 \quad 67 \quad 1158$ carea $=\% 24$ ROOT $\% 29 /$. do?rf=y, (Accessed 16 April 2012).

United Nations, Economic and Social Council. 2009. Flow of Financial Resources for Assisting in the Implementation of the Programme of Action of the International Conference on Population and Development. Paper presented at Commission on Population and Development, 42nd Session. New York: United Nations. (Accessed on 15 July, 2009).

United Nations Population Fund. 2010. Reproductive Health Costing Tool. http://www.who.int/pmnch/topics/economics/costing_tools/en/ index 15.html.

Vlassoff M, Fetters T, Kumbi S, Singh S. 2012. The health system cost of postabortion care in Ethiopia. International Journal of Gynecology and Obstetrics 118S: S63-9.
Vlassoff M, Shearer J, Walker D, Lucas H. 2008. Economic Impact of Unsafe Abortion-Related Morbidity and Mortality: Evidence and Estimation Challenges. Research Report No. 59. Brighton, UK: Institute of Development Studies.

Vlassoff M, Sundaram A, Remez L, Mugisha F, Bankole A. 2009a. Benefits of Meeting the Contraceptive Needs of Ugandan Women. In Brief 2009 Series, No. 4. New York: Guttmacher Institute.

Vlassoff M, Walker D, Shearer J, Newlands D, Singh S. 2009b. Estimates of health care system costs of unsafe abortion in Africa and Latin America. International Perspectives on Sexual and Reproductive Health 32: 114-21.

Weissman E, Sentumbwe O, Mbonye AK et al. 1999. Uganda Safe Motherhood Programme Costing Study. Geneva: World Health Organization.

Woog V, Singh S, Bankole A. 2007. A review of the evidence on the costs of postabortion care in Africa. In: Lule E, Singh S, Chowdhury SA (eds). Fertility Regulation Behaviors and Their Costs. Washington DC: World Bank, pp. 40-64.

World Bank. 2010. World Development Indicators. Www.worldbank.org/ data/, accessed 15 July 2010.

World Health Organization (WHO). 1999. Mother-Baby Package Costing Spreadsheet: Users Guide. Geneva: World Health Organization.

WHO. 2011. Health System Statistics. www.who.int/whosis/en/, accessed 1 December 2011.

WHO. 2012. Trends in Maternal Mortality: 1990 to 2010. Geneva: World Health Organization.

Xu K, Evans DB, Kadama P, Nabyonga J, Ogwal PO, Aguilar AM. 2005. The Elimination of User Fees in Uganda: Impact on Utilization and Catastrophic Health Expenditures. Discussion Paper 2005-4. Geneva: World Health Organization. 